\title{
Adoption the Competence Exam as an Innovation Approach to Improve Nurses' Quality
}

\author{
Mohammed Baqer Al-Jubouri", Mohammed Baqer Abd Ali \\ College of Nursing, University of Baghdad, Bab Al Muadham, Baghdad, Iraq \\ Email address: \\ maaljubouri@conursing.uobaghdad.edu.iq (M. B. Al-Jubouri), mhabdali1@my.okcu.edu (M. B. A. Ali) \\ ${ }^{*}$ Corresponding author
}

To cite this article:

Mohammed Baqer Al-Jubouri, Mohammed Baqer Abd Ali. Adoption the Competence Exam as an Innovation Approach to Improve Nurses' Quality. American Journal of Nursing Science. Vol. 10, No. 3, 2021, pp. 182-184. doi: 10.11648/j.ajns.20211003.18

Received: May 13, 2021; Accepted: May 31, 2021; Published: June 25, 2021

\begin{abstract}
Background: The competence exam is an action to develop nursing students' competencies before graduation to be prepared for clinical settings. Many nursing schools around the world require passing standardized tests in terms of graduation in a nursing program. However, there is no such an exam in Iraq. Method: Rogers Diffusion of Innovation Theory is helpful to determine the adoption of a behavior and to decide which components need extra effort if diffusion is to occur. This theory is used to apply the competence exam as an innovative approach to improve nurses' quality in Iraq. Results: Organization, faculty, and curriculum are the main three concepts that can be integrated based on Rogers Diffusion of Innovation Theory to adopt a competence exam. The outcome would affect nurses' quality directly, and an evaluation can determine the effectiveness of this innovation Conclusion: Adopting a competence exam prepares nursing students for the real clinical settings.
\end{abstract}

Keywords: Competence Exam, Innovation Theory, Nurse, Quality

\section{Introduction}

Nursing competency, in the United States (U.S.), is handled by The National Council of State Boards of Nursing (NCSBN) that ensures that all graduate nurses must pass the National Council Licensure Examination (NCLEX) exam to assess their competencies before they are employed as nurses [1]. The purpose of this policy is to maintain patients' safety and public protection. In Iraq, there is no such policy and exams to protect the public, and graduated nurses are employed by the Iraqi Ministry of Health without the NCLEX exam or any other competence exam. Herrman and Johnson [2] stated that it is essential for nursing schools to assist students to build the right knowledge, increase their self-confidence, and work as a professional in the clinical area. If this arises, they are able to pass the NCLEX exam and become registered nurses. In the U.S., nurses' licenses, which are arranged through stats' boards of nursing, sponsor a minimum level of competence. Cowin, et al. [3] mentioned that the nurses' performance should be assessed through a regular competency assessment.

The Iraqi Ministry of Justice [4] represented the decision of the Council of Representatives (number 97) for the law (number 96) regarding practicing the profession of nursing and midwifery. This law's goal is to develop the profession of nursing and midwifery in a way that maintain the public safety. However, there is no prepared plan about how to control and guide this profession. Al Hilfi, Lafta, and Burnham [5] stated that there is no plan that focuses on nurses based on well-organized and applicable criteria that can guarantee the delivery of a highly competent care. As a result, the competence exam can be a good strategy to guarantee the minimum level of competence [6].

The competence exam, in this project, is an action from the academic side (University of Baghdad) to develop nursing students' competencies before graduation to be prepared for clinical settings. Nursing students have had opportunities during the four academic years to achieve practice experiences from clinical training. However, there is a gap between the application of those experiences and real clinical situations [7]. Also, Romyn et al. [8] declared that newly graduated nurses are not prepared enough to be in the workforce. Therefore, many schools require passing standardized tests in terms of graduation [7, p. 68]. Indeed, education can increase the level of students' competence before graduation, so employers need less time to increase 
new graduate's competence. Theisen and Sandau [6] mentioned that a part of nursing competence can be built during the educational courses in nursing schools to transit new graduate nurses into competent nurses. Therefore, the idea of having a competence exam for nursing students in Iraq is a vital concept to improve Iraqi nurses' quality.

The researchers would apply the competence exam in their workplace (University of Baghdad) for the senior students. Nursing students would not be graduated unless they pass this exam. Because the competence exam is a new idea in Iraq, it needs to be adopted by the stakeholders (Ministry of Higher Education, Ministry of Health, University of Baghdad, nursing faculty, and nursing students). The theory that would be used to apply the competence exam is Rogers Diffusion of Innovation Theory.

\section{Project \& Team Knowledge Base}

Rogers has developed one of the better-known theoretical approaches to diffusion of innovation [9]. This theoretical framework is helpful to determine the adoption of a particular behavior and to decide which components need extra effort if diffusion is to occur. This theoretical framework includes a consideration of aspects of the innovation, style of communication, steps in decisionmaking, and the social context [10].

Diffusion is the process by which an innovation is communicated through specific channels over time among the members of a social system [11]. Given that decisions are not authoritative or collective, each member of the social system faces his/her own innovation-decision that follows a 5-step process [11]:

1) Knowledge - person becomes aware of an innovation and has some idea of how it functions,

2) Persuasion - person forms a favorable or unfavorable attitude toward the innovation,

3) Decision - person engages in activities that lead to a choice to adopt or reject the innovation,

4) Implementation - person puts an innovation into use,

5) Confirmation - person evaluates the results of an innovation-decision already made.

According to Rogers [10], adoption of a new idea does not occur at the same time in a social system; some people are more predisposed to accept the innovation than others do. The traits of people who adopt an innovation early are unlike the people who adopt an innovation later (Boston University School of Public Health, 2016). Rogers [12] defined the adopter categories as "the classifications of members of a social system on the basis of innovativeness" (p. 22). This classification includes innovators, early adopters, early majority, late majority, and laggards. In each adopter category, individuals are similar in terms of their innovativeness: "Innovativeness is the degree to which an individual or other unit of adoption is relatively earlier in adopting new ideas than other members of a system" [12, p. 22]. Braak [13] described innovativeness as "a relativelystable, socially-constructed, innovation-dependent characteristic that indicates an individual's willingness to change his or her familiar practices" (p. 144). For Rogers, innovativeness helped in understanding the desired and main behavior in the innovation-decision process. In order to implement our project, we need to move; along with decision makers in our college; step by step according to the aforementioned 5-steps process.

\section{Key Concepts for Planning}

The concepts that the researchers will integrate throughout the project plan include the organization, faculty, and curriculum. Generally, organizations in Iraq play significant roles in implementing new ideas. Since the administrative system in Iraq is vertical in nature, so directions emerge from the higher authorities (ministers, vice ministers, etc.) to the lower (deans). Because most of leaders in Iraq are laggard, the probability of adopting our project (the competence exam) is weak. It is difficult to persuade the Minister of Higher Education and the Minister of Health in Iraq to accept the idea of the competence exam.

For faculty, they are responsible for making appropriate questions for the competence exam. Lenburg, et al. [14] suggested eight competencies that must be included in the competence exam, which are assessment and intervention skills, communication skills, critical reasoning and problem solving skills, human caring and relationship skills, management skills, leadership and teaching skills, and knowledge integration skills. The faculty should also consider the characteristics of the test items in the competence exam. Furthermore, faculty have to write all test items within a high cognitive level according to Bloom's Taxonomy [15].

Regarding the curriculum, it should contain materials that prepare students to take the competence exam. Also, the curriculum must include effective strategies that enable students to pass the competence exam. In addition, several areas of content must be addressed in the competence exam; based on the curriculum, such as nursing process, caring, communication, documentation, teaching, and learning that enhance nursing students' quality [1].

\section{Project Plan \& Evaluation}

The idea of implementing the competence exam in nursing would be applied, at first, at the College of Nursing/ University of Baghdad as the oldest and biggest among nursing colleges in Iraq. The faculty members, nursing students, and administrators in this college would play significant roles in the success of this idea. The objectives of this project include 1) ensuring the success of this innovation via assessing students' learning achievements, 2) applying and conducting the competence exam as a standard approach that must be applied in all nursing colleges in Iraq within five years, 3) improving nurses' quality in Iraq, which in turn, enhances patient safety, minimizes hospitalization, and reduces healthcare costs for both clients and healthcare organizations. 
The evaluation process that can serve to determine the effectiveness of this innovation includes 1) continuous evaluation of the competence exam and nursing students' achievement, 2) continuous follow-up for the quality of nursing care that is delivered by nurses who pass the competence exam successfully. This process requires collecting data from the College of Nursing regarding the achievement of nursing students throughout five years from the time of applying of this idea. Thus, data should be collected concerning the quality of nursing services from all health care settings that will employ nurses who should pass the competence exam. The collected data will help in making a decision about the efficacy of this innovation.

\section{Conclusion, Insight \& Impressions}

The project of applying the competence exam in College of Nursing at University of Baghdad is a new idea that aims mainly to improve Iraqi nurses' quality. This new idea needs to be adopted based on the five steps (knowledge, persuasion, decision, implementation, and confirmation) of Rogers Diffusion of Innovation Theory. The most difficult part in applying this idea is to persuade officials in the Ministry of Higher Education and Ministry of Health in Iraq.

This project can ensure the availability of highly competent nurses who can work in healthcare settings and can deliver high quality care for clients. The researchers recommend collecting data related to benefits of this project based on the project's objectives. Results attained from this data collection can be helpful to make a decision regarding maintaining, revising, or abolishing this project. Moreover, this process is just like the lighting of a fire that will help in improving the healthcare delivery system, the educational institutions, and the healthcare organizations. Consequently, the success of this new idea would open the door toward issuing a new policy of applying and conducting the NCLEX exam in all colleges of nursing in Iraq.

\section{References}

[1] National Council of State Boards of Nursing. (2014). NCLEX examination. Retrieved from https://www.ncsbn.org/nclex.htm

[2] Herrman, J. W., \& Johnson, A. (2009). From beta-blockers to boot camp: Preparing students for the NCLEX-RN. Nursing Education Perspectives, 30 (6), 384-388.
[3] Cowin, L. S., Hengstberger - Sims, C., Eagar, S. C., Gregory, L., Andrew, S., \& Rolley, J. (2008). Competency measurements: Testing convergent validity for two measures. Journal of Advanced Nursing, 64 (3), 272-277.

[4] Iraqi Ministry of Justice. (2012). The Law of practicing the profession of nursing and midwifery. Iraqi Facts, 4260. Retrieved from http://www.moj.gov.iq/uploaded/4260.pdf

[5] Al Hilfi, T. K., Lafta, R., \& Burnham, G. (2013). Health services in Iraq. The Lancet, 381 (9870), 939-948. Retrieved from

http://www.ed.ac.uk/polopoly_fs/1.115933!/fileManager/Lanc et $\% 20$ paper\%20Thamer.pdf

[6] Theisen, J. L., \& Sandau, K. E. (2013). Competency of new graduate nurses: a review of their weaknesses and strategies for success. Journal of Continuing Education in Nursing, 44 (9), 406-414.

[7] Burns, P., \& Poster, E. C. (2008). Competency development in new registered nurse graduates: closing the gap between education and practice. Journal of Continuing Education in Nursing, 39 (2), 67-73.

[8] Romyn, D. M., Linton, N., Giblin, C., Hendrickson, B., Houger Limacher, L., Murray, C.,... \& Zimmel, C. M. (2009). Successful transition of the new graduate nurse. International Journal of Nursing Education Scholarship, 6 (1).

[9] Sanson-Fisher, R. (2004). Diffusion of innovation theory for clinical change. The Medical Journal of Australia, 180 (6), 12.

[10] Rogers, E. (1983). Diffusion of innovations. New York: Free Press.

[11] Orr, G. (2003). Diffusion of Innovations, by Everett Rogers (1995). Retrieved from https://web.stanford.edu/class/symbsys205/Diffusion \%20of\% 20Innovations.htm

[12] Rogers, E. M. (2003). Diffusion of innovations (5th ed.). New York: Free Press.

[13] Braak, J. V. (2001). Individual characteristics influencing teachers' class use of computers. Journal of Educational Computing Research, 25 (2), 141-157.

[14] Lenburg, C. B., Abdur-Rahman, V. Z., Spencer, T. S., Boyer, S. A., \& Klein, C. J. (2011). Implementing the COPA model in nursing education and practice settings: Promoting competence, quality care, and patient safety. Nursing Education Perspectives, 32 (5), 290-296.

[15] Wendt, A. (2003). The NCLEX-RN (R) Examination: Charting the course of nursing practice. Nurse Educator, 28 (6), 276-280 